\title{
EM BUSCA DE UM OBJETO ESQUECIDO A política e as políticas do urbano no Brasil*
}

\section{Eduardo Cesar Leão Marques}

Universidade de São Paulo (USP), São Paulo - SP, Brasil. E-mail: ecmarq@uol.com.br

DOI: $10.17666 / 329509 / 2017$

Sabemos pouquíssimo sobre as especificidades da política e das políticas nas cidades brasileiras. Isso é surpreendente, pois $84 \%$ de nossa população vivia em cidades e $66 \%$ morava em municípios com mais de 50 mil habitantes em 2010, segundo o IBGE. Esse silêncio é ainda mais surpreendente, pois clássicos de nossa política, como Instituiçóes politicas brasileiras, de Oliveira Vianna (1949), e Coronelismo, enxada e voto, de Victor Nunes Leal (1948), tratavam justamente da relação entre o sistema político e o poder local, considerado central para se compreender a política brasileira. Também aqui, portanto, se considerava que all politics is local politics, como sustentou o norte-americano Byron Price em 1932.

* Agradeço a leitura atenta e os comentários detalhados de Renata Bichir, Camila Saraiva e Valéria Macedo à versão anterior deste texto.

Artigo recebido em 24/03/2016

Artigo aprovado em 07/04/2017
O silêncio recente parece considerar que a nacionalização dos partidos a partir do período democrático populista e a centralizaçáo política do período Vargas e do regime militar tiraram das cidades todo dinamismo político. Por outro lado, esses momentos foram mediados por descentralização nos períodos democrático populista e no atual, embora nesse último combinando centralização e descentralização por políticas e fases de seus ciclos. Desde a última redemocratização, o nível local voltou a ganhar interesse empírico para a ciência política com o retorno da competição político-eleitoral às grandes cidades e as reformas federalistas de políticas públicas, embora a literatura brasileira sobre política tenha analisado as cidades apenas quando tratava de participação social. Mesmo no debate recente sobre federalismo, o nível local é a escala menos tematizada, talvez por acreditar-se que as políticas federais tornariam os governos locais meros implementadores "técnicos", sem espaço para discricionariedade. Embora a ca- 
pacidade de indução federal varie entre políticas, é certamente tênue para as políticas do urbano - de construção do quadro construído e de gestão dos serviços e equipamentos que caracterizam as cidades. Este artigo pretende iniciar a tarefa de analisar a política e as políticas do urbano, sugerindo caminhos para a sua compreensão.

Ainda que o silêncio dos debates nacionais não se justifique, ele é compreensível (e tem ecos internacionais), considerando as premissas abraçadas pelas duas principais comunidades profissionais e acadêmicas que poderiam tratar do assunto. De um lado, os temas urbanos acabaram explorados em nossas ciências sociais principalmente pela sociologia, focando dimensóes societais de poder, mas sem tematizar em detalhes as instituiçóes políticas e suas açōes. Os cientistas políticos, que as deveriam analisar por dever de ofício, pouco trataram do urbano. De outro, o campo dos estudos urbanos, para onde convergem geógrafos, planejadores e sociólogos, quase sempre privilegiou processos e atores societais e năo se interessou pelas instituiçóes.

Este artigo parte da premissa de que a política do urbano apresenta especificidades pela sua associação com o espaço urbano, gerando elementos de três ordens: espacialidades, percepçóes e propinquidade, além da existência de vários atores específicos da cidade com comportamento peculiar. A compreensão dessas dimensóes da política passa pela consideraçáo de um conjunto específico de atores historicamente constituídos - elites políticas e burocracias locais, capitais do urbano e atores da sociedade civil organizada -, no interior de redes formadas ao longo das trajetórias desses indivíduos (e desses setores de política pública), e cercados pelas instituiçôes do setor, o que denomino de tecido relacional do Estado. Conceitos recentes como governança ajudam a compreender as açóes desses atores nas redes, mas apenas se considerarmos os padrōes de relaçẫo presentes em nível local em várias políticas distintas concomitantemente, e se esses forem compreendidos simultaneamente como lugar de ação social e como produtos históricos da formação do Estado em nível local. Uma ampla agenda de pesquisas sobre a política do urbano se coloca à frente, e contribuir para a construção de um arcabouço teórico para o seu estudo é o objetivo deste trabalho.
O artigo está dividido em quatro seçôes, além desta introdução e de uma conclusão. Na seção que se segue, analiso a especificidade da política e das políticas do urbano. Na segunda e na terceira, recupero as tradiçóes do estudo da política da cidade e em seguida discuto o abismo analítico entre estudos urbanos e ciência política. Na quarta parte, sempre dialogando com o caso brasileiro, apresento os principais elementos a considerar no estudo da política e das políticas do urbano - instituições, agências e processos de produção de políticas; atores societais e suas relaçóes; e legados históricos da política e das políticas. Embora presentes na política em geral, todos esses elementos apresentam importantes especificidades urbanas. Ao final, retomo os principais elementos discutidos à guisa de conclusão.

\section{A especificidade da política do urbano}

Antes de tudo, é fundamental definir o que entendo por política e políticas do urbano, visto que há visōes disciplinares distintas sobre essas definiçōes (Davies e Imbroscio, 2005; Judd, 2005). A política do urbano é entendida aqui como as açôes, as negociaçôes, as alianças e os conflitos acerca das políticas públicas urbanas e do poder das (e nas) instituiçóes políticas da cidade, assim como as próprias instituiçôes. Em primeiro lugar, vale destacar que embora haja dimensões do poder associadas à vida cotidiana $\mathrm{e}$ às relaçóes interpessoais interessam-me aqui os elementos ligados às políticas e às instituiçôes estatais. Seguindo Jobert e Muller (1987), políticas públicas são entendidas como o Estado em ação, mas políticas públicas urbanas incluem, em especial, as açōes do Estado que incidem sobre o tecido urbano, seus territórios e a vida urbana. Não me refiro a níveis de governo; embora no Brasil o município esteja diretamente implicado, políticas estaduais e federais também produzem impactos. Estáo aqui incluídas as políticas de produçâo direta do espaço construído, como transportes, infraestrutura e habitação, mas também a regulação estatal sobre açōes privadas, como o licenciamento de empreendimentos, por exemplo. Entretanto, as políticas do urbano também incluem açóes do Estado que influenciam a sociabilidade e a vida urbana, embora sem produzir 
diretamente o ambiente construído. Nesses casos, a política cria e altera o espaço urbano ao influenciar a maneira pela qual os habitantes vivenciam o cotidiano da cidade. A implementação local das políticas sociais, por exemplo, gera fluxos espaciais de agentes públicos e usuários, ao mesmo tempo que se apoia em estratégias espaciais de localização de equipamentos e programas. Evidentemente, muitas outras políticas influem nas cidades, como as políticas de emprego e renda, as políticas econômicas, as políticas migratórias etc. Interessa-me aqui, contudo, entender os processos que cercam a política e as políticas da cidade, em vez de incluir todas aquelas que ocorrem na cidade.

Este artigo parte da premissa da existência de uma especificidade da política e das políticas urbanas. A característica desse objeto é ontológica e diz respeito à sua relaçáo com o espaço urbano, entendido como o conjunto relacionado (e socialmente construído) de vizinhanças, contiguidades, distâncias e fluxos criados e recriados pelos atores do urbano, assim como os significados que dão sentido a esses atores. Dessa forma, o espaço define e constitui as disputas políticas, as instituições, a operaçáo dos governos e a política eleitoral nas cidades. Os modelos usuais da ciência política explicam diversas dessas dimensóes, mas outras necessitam de conceitos próprios, sobretudo quando se passa da cidade como unidade (em que os modelos da ciência política trabalham melhor) para dimensóes e processos internos a ela (em que a interação com o espaço cria especificidades).

O ponto de partida para entendermos as relações entre política e espaço é a superação de uma visão de espaço como plano cartesiano ou como página em branco, no sentido de incorporar a dimensão do social (Lefebvre, 1976) produzida por interaçóes sociais, múltiplas e em contínua mudança. O espaço é, então, uma dimensão constitutiva da política, pois a política se localiza no tempo e no espaço (Massey, 2005). Logo, como não existe política fora do tempo, náo é possível pensar política fora do espaço. ${ }^{1}$

Podemos construir uma analogia inicial da interação entre espaço e política com os efeitos das instituições, já amplamente discutidos pelo neoinstitucionalismo (Skocpol, 1992). O espaço consti- tui-se em uma estrutura de médio alcance, que é constantemente construída e alterada pelos atores, mas que se apresenta para eles em um dado momento como um conjunto de constrangimentos e possibilidades, emoldurando a política, influenciando suas estratégias e a formação de preferências e visões de mundo. Reinterpretando Marx, podemos dizer que os homens fazem o espaço, mas não o fazem como querem.

As relações entre espaço e instituiçóes podem ser divididas em três dimensóes interpenetradas (Marques, 2016a e b). Em primeiro lugar, o espaço é dimensão constitutiva das instituições e das práticas políticas, pois estas apresentam sempre uma dimensão espacial, o que a geografia denomina espacialidade dos processos. Isso envolve as facetas espaciais das instituições, como, por exemplo, os distritos eleitorais na representação política, as escalas do federalismo nas políticas públicas, os limites territoriais dos Estados nacionais e os trajetos das campanhas eleitorais ou as estratégias espaciais de mobilização de movimentos sociais.

Em segundo lugar, o espaço ocupa um importante papel na formação das percepções políticas, pois "a forma que imaginamos o espaço tem consequências" (Massey, 2005, p. 4). O espaço é uma das dimensões a moldar as percepções e as preferências sobre política, assim como as estratégias e as açóes possíveis, gerando percepçóes espaciais (Méo, 1991). Exemplificando essa dimensão, podemos pensar no lugar da ideia de periferia em expressóes artísticas de protesto (como o Rap), na formação de identidades regionais (e seus separatismos) ou na relação entre padrôes de segregação residencial e percepções sobre justiça social e desigualdades.

O terceiro enfoque é mais concreto e diz respeito aos padrốes de localizaçóes, contiguidades, distâncias e fluxos, o que Peter John (2005) define como propinquidade. Em certo sentido, a propinquidade (dimensão espacial concreta) representa a cristalização de certas espacialidades (dimensão das práticas). Incluem-se aqui tanto os efeitos do espaço herdado sobre o qual a política age, quanto os efeitos concretos das açóes políticas sobre o espaço. A existência de legados espaciais prévios estabelece constrangimentos e possibilidades, gerando incentivos e desincentivos para certas açóes, assim como 
influenciando processos. Esse efeito está ligado a localizaçóes pontuais, como os locais das escolas de melhor qualidade e seus distritos, com consequências para as desigualdades educacionais e as estratégias das famílias. Mas os fluxos da política e das políticas também apresentam efeito similar, como o traçado das linhas de ônibus e de metrô, com efeitos similares sobre estratégias locacionais e decisôes cotidianas. As ações políticas, por seu turno, reconstroem cotidianamente tais localizaçóes, fluxos, contiguidades e distâncias.

As ações dos atores políticos (inclusive do Estado) especializam-se sobre essas estruturas espaciais herdadas. Sabendo disso, os atores adiantam estrategicamente os efeitos do espaço sobre suas açóes, adaptando-as. Além disso, as localizaçóes indicadas levam a superposiçóes no espaço, visto que é no espaço que os cidadãos encontram as políticas (e vice-versa), os políticos encontram os eleitores e as estruturas de representação encontram os representados. Como as cidades são segregadas por grupos sociais, o "onde" define quase sempre o "quem", e a espacialidade das políticas influencia seu alcance e elegibilidade (Scott, 1998). Isso pode ajudar as políticas, se estratégias territoriais forem pensadas e incorporadas, como nas políticas europeias de mistura social ou nas estratégias de busca ativa das políticas assistenciais brasileiras recentes (Torres, 2005). Entretanto, também pode reforçar desigualdades e enviesar açóes, como nos casos de zoneamentos urbanos exclusivistas ou da concentração de recursos em escolas de melhor performance, por exemplo. Em qualquer situação, as ações e os interesses políticos dos vários atores especializam-se com tais localizaçôes e fluxos, pois estes especificam valorizaçôes da terra, benefícios para moradores e usuários desses espaços e votos de eleitores impactados localmente. No caso da política do urbano, as formas pelas quais policies produzem politics são mediadas pelo espaço.

Adicionalmente, mas não menos importante, a política do urbano envolve processos e atores próprios das cidades. Uma parte deles está associada com a produção do espaço diretamente e inclui o que denomino "capitais do urbano" - incorporadores, construtores de infraestruturas, prestadores de serviços urbanos (Marques, 2016b). Esses atores privados têm os seus processos de valorização asso- ciados diretamente com a construção, a manutenção e a operação da própria cidade.

Além deles, é importante citar membros da classe política que têm no urbano sua escala de ação e suas formas de reprodução - políticos locais, operadores políticos locais de partidos, prefeitos e vereadores, incluindo os de reduto eleitoral, mas também outros atados a eleitores e interesses econômicos que operam na escala da cidade. Outro conjunto amplo de atores tipicamente urbanos são as burocracias de nível da rua. Esses se caracterizam pela entrega direta de políticas e, como a maior parte das políticas é entregue na cidade, o espaço é uma dimensão central de suas açóes.

\section{As tradiçóes do estudo da política da cidade}

O debate internacional sobre a política do urbano nasceu nos Estados Unidos nos anos de 1950 e 1960. Embora a cidade seja um objeto muito mais antigo, as análises pouco trataram de instituições políticas, governo ou políticas, concentrando-se em aspectos macrossociológicos, como em Karl Marx e Max Weber, ou centrando a atenção na sociabilidade nos centros urbanos, como em Georg Simmel e na Escola da Chicago.

Apenas nos anos de 1950, o chamado community power debate iniciou a discussão sistemática do poder político na cidade. O debate é por demais conhecido, mas uma rápida recuperaçáo ajuda a situar os passos posteriores da literatura, visto que ele informou tanto os estudos urbanos quanto a ciência política, sendo, na verdade, o último momento de diálogo intenso entre esses campos.

Em 1953, Floyd Hunter publicou seu estudo sobre o poder em Atlanta, sustentando que a cidade era dominada por um grupo limitado de atores políticos de forma ampla e continuada. Esse argumento convergia com a interpretação de Mills (1956) de que na democracia representativa norte-americana o poder da elite seria oriundo da posição social de seus integrantes em uma sociedade com grandes desigualdades. A reprodução desse poder passaria pela reprodução da sociedade, pela herança de ativos e propriedades, mas também pela socialização em escolas e universidades de elite, 
casamentos e amizades e locais de sociabilidade. Esses processos reproduziriam as posiçóes e, consequentemente, o poder associado a elas.

Contra essa interpretação, autores do que viria a se denominar "pluralismo" estudaram outras cidades, sustentando a pluralidade da democracia norte-americana a partir do local. O principal deles foi Dahl (1961), que analisou historicamente a política em New Haven. Nesse caso, poder político não era pensado como algo potencial e posicional, mas como a capacidade de um grupo de agir para fazer prevalecer seus interesses na formação de governos e políticas. As dinâmicas da política seriam originadas nos grupos de interesse, que representam as verdadeiras unidades de ação. Dahl sustentou que, apesar de intensas, as desigualdades sociais nos Estados Unidos não seriam cumulativas em uma sociedade com economia de mercado e governo representativo democrático. A trajetória histórica do país teria contribuído para uma pluralização da sociedade e da política, não havendo grupos capazes de controlar a política de forma ampla e sustentada, embora em alguns momentos pudessem se observar coalizões relativamente estáveis, mas que se dissolveriam com o passar do tempo.

Nos anos de 1960 e 1970, um terceiro corpo teórico entrou em cena com o forte impacto do marxismo sobre os estudos urbanos. Também esse debate é por demais conhecido e analisado para ser resenhado aqui. Entretanto, ao menos três perspectivas devem ser citadas, associadas respectivamente a Henri Lefebvre, à sociologia estruturalista (Manuel Castells e Jean Lojkine) e à geografia crítica, principalmente de David Harvey. Em nenhum desses autores, entretanto, as instituiçóes políticas ou a política foram objeto de atenção particular, havendo pouco espaço para a contingência que marca o campo da política. ${ }^{2}$

Mas é importante destacar as contribuições dessa literatura que focaram elementos específicos, muito relevantes para o estudo da política do urbano. Em primeiro lugar, as contribuições a respeito dos capitais do urbano, em especial do capital imobiliário (Topalov, 1973), especificando seus circuitos de valorização e suas relações com o espaço. Por outro lado, as associaçóes entre os padróes de segregação na cidade e a distribuição dos equipamentos urbanos tiveram o seu ápice em trabalhos precisos como o estudo de Pinçon-Charlot, Preteceille e Rendu (1979). Embora não dissessem respeito ao Estado e às instituiçóes políticas do urbano, os avanços nessas duas linhas de análise apresentaram aprendizados importantes para a política nas (e das) cidades.

Vale dizer que a sociologia urbana brasileira se iniciou nesse momento. Obras anteriores do debate nacional já haviam discutido as características do capitalismo nacional - baixos salários e trabalho informal como elemento central da posição dependente e periférica do país na divisão internacional do trabalho. Kowarick (1979), contudo, inovou ao conectar essas dimensóes com as condições urbanas concretas. Os padrôes de exploração vigentes encontrariam nas grandes metrópoles outras formas de espoliação viabilizadas pelos regimes autoritários da América Latina. A produção das periferias, baseada em autoconstruçâo dentro de loteamentos irregulares ou em favelas com escassa presença estatal, passou a ser objeto de preocupação a partir de então, o que levou a uma fecunda tradição de estudos urbanos, como por exemplo a obra organizada por Maricato (1982). Apesar da contribuição dessa literatura para o entendimento de nossas cidades, poucas foram as pistas deixadas por ela para desvendar a política do urbano.

Os anos de 1970 e 1980 assistiram ainda ao surgimento internacional de duas outras visóes sobre a política da cidade - as máquinas de crescimento e os regimes urbanos. A ideia das máquinas de crescimento teve origem nos trabalhos de Moloch (1976), sustentando que o federalismo fiscal norte-americano criou uma situação praticamente inexorável para as elites políticas locais. $\mathrm{O}$ escasso financiamento dos governos municipais teria deixado as cidades sem fontes próprias de recurso e sem repasses sistemáticos de outros níveis governamentais. Isso teria levado as cidades a depender fundamentalmente de investidores privados para desenvolver políticas. As coalizōes urbanas, portanto, buscaram construir ciclos de crescimento baseados em renovação urbana e promoção imobiliária, associando as elites políticas locais aos interesses $\mathrm{da}$ terra, em especial aos da incorporação. Embora esse modelo de interpretação tenha sido muito influente desde então, autores como Harding (1997) mos- 
traram que, na Europa, as elites políticas locais são muito menos dependentes dos capitais do urbano em virtude de os governos locais terem fontes de financiamento e repasses dos governos centrais, além de serem grandes proprietários de terras. Outros autores mostraram que mesmo nos Estados Unidos as cidades adotaram outros tipos de coalizão, até mesmo com políticas anticrescimento.

Esses argumentos dialogam com o caso brasileiro, já que a recomposição de nosso federalismo tem sido uma das principais questóes em torno das reformas de políticas (Arretche, 2012a). Embora a maioria das políticas urbanas seja uma atribuição formal dos governos locais, os legados de políticas prévias e aquelas gestadas em esferas superiores influenciam intensamente as políticas nas (e das) cidades. Além disso, os níveis locais de poder têm acesso a um conjunto significativo de recursos financeiros por repasses automáticos (via Fundo de Participação dos Municípios) ou por repasses específicos condicionados por políticas. Assim, o desenho do federalismo brasileiro diferencia a política do nosso urbano das máquinas de crescimento de Moloch (1976), e a relação das elites locais com os interesses econômicos não é marcada pelo mesmo tipo de dependência. Como será destacado a seguir, a associação entre esses atores parece ser mais política, mais mediada pelo acesso ao fundo público e mais ligada às eleiçôes do que à promoção de certas políticas vinculadas à terra (Marques, 2016a).

No início da década de 1980 forjou-se outro modelo explicativo nos Estados Unidos em diálogo mais claro (e crítico) com a tradição pluralista. Sua origem remonta ao trabalho de Elkin (1985) sobre regimes urbanos. Para ele, a máquina de crescimento simplifica uma situação histórica que teve nuances importantes nas cidades norte-americanas. Embora grande parte das decisóes se encontre nas mãos de proprietários privados, os políticos também precisam construir vitórias eleitorais estáveis, o que nem sempre se alinha com os interesses do crescimento. Além disso, essas duas dimensões dependem de burocracias funcionais que fornecem os serviços necessários para o desenvolvimento econômico e as reeleiçôes.

A ideia dos regimes urbanos foi aperfeiçoada por Stone (1993), retornando à política de Atlanta (analisada por Floyd Hunter) entre 1946 e 1988. O resultado é talvez o modelo recente mais influente sobre a política do urbano. Stone partiu de uma absorção crítica do pluralismo, rejeitando a ideia de que os grupos tenham poder equivalente e destacando, nesse sentido, a força dos atores econômicos. Para ele, portanto, os interesses dos negócios muitas vezes prevalecem (como enfatizado pelas growth machines), pois isso também seria do interesse dos agentes estatais, considerando sua competência em realizar açóes e políticas. O Estado em nível local poderia por vezes impor sua vontade, mas como as capacidades estão nas mãos do setor privado, o mais comum seria que o governo se ativesse ao papel de coordenador. Para Stone, portanto, poder não representa uma imposição sobre outros agentes, mas a capacidade de realizar, deslocando a ideia de poder de controle para a produção.

Em outras palavras, os atores estatais seriam autônomos (como no pluralismo), mas os empresários teriam uma posição privilegiada (como no marxismo, na teoria das elites e na tese das máquinas de crescimento). Dinâmicas eleitorais e composição do eleitorado seriam centrais, assim como os processos associados às burocracias e aos atores estatais. Como consequência, regimes urbanos seriam arranjos informais entre agentes públicos e privados (políticos eleitos, empresas privadas, comunidades profissionais e funcionários do Estado), que operariam conjuntamente para tomar decisóes públicas e realizar açōes. Stone, portanto, abriu espaço para a explicação de variabilidade empírica e as diferenciaçôes de regimes, embora pressuponha a existência de um único regime em certo local e período.

\section{As raízes do vazio analítico da política do urbano}

As premissas dos dois principais campos de estudo envolvidos potencialmente com o estudo da política do urbano - ciência política e estudos urbanos - levaram a uma grande ignorância mútua com relação a suas produçóes respectivas.

A maior parte dos cientistas políticos considera não haver especificidades na política e nas políticas locais, sendo estas apenas versóes regionais de 
processos supralocais. ${ }^{3}$ Seguindo essa visão, estudar a política local (e políticas locais) seria uma atividade menor, pois os processos "realmente" relevantes aconteceriam alhures, sendo o espaço apenas uma folha em branco a ser preenchida. É verdade que se deve sempre considerar simultaneamente as escalas local, regional, nacional e internacional. É igualmente correto que estudos recentes sobre geografia eleitoral, implementação local de políticas e mobilização partidária do eleitorado começam a trazer a escala local para o estudo da política no Brasil. Entretanto, uma melhor compreensão da política do urbano depende da incorporaçáo do espaço, e não apenas da escala local, ao estudo da política. Brincando com a formulação clássica de Harold Lasswel, a política não é apenas sobre "who gets what, when and how", mas também "where". Mais do que uma escala de análise, trata-se de considerar a ontologia espacial da política.

Por outro lado, desde os anos de 1970 disseminou-se entre os analistas das cidades a premissa de que o Estado e a política seriam epifenômenos de processos produzidos por atores e processos situados na sociedade, em parte por influência de várias correntes da literatura crítica (Castells, 1983; Harvey, 1980). Nesse sentido, não seria necessário estudá-los, mas apenas focar a atenção em processos societais, observando seus efeitos sobre as instituiçóes políticas. Como já demonstrou ampla e variada literatura, essa premissa está também equivocada, pois os processos no (e do) Estado e suas instituiçóes, assim como as disputas concretas de poder por elas (e no seu interior), seguem dinâmicas próprias, mesmo que possam estar influenciadas por processos ocorridos na sociedade ou na economia.

Internacionalmente, as razóes desse vazio têm sido debatidas intensamente. Stone (2010) sustentou que os estudos urbanos se desenvolveram de forma relativamente isolada, pois o mainstream da ciência política, partindo de premissas pluralistas separou política e economia, silenciou sobre a questão da desigualdade e acreditou que mandato e autorização legislativos seriam equivalentes à produção de políticas, desconsiderando a sua implementação. Judd (2005), em contrapartida, construiu uma arguta (e ácida) crítica a esse desconhecimento mútuo. Para ele, esse apartamento é explicado a um só tempo pelo fato de, nas décadas de 1960 e 1970, os estudos urbanos terem sido capturados pela política e de a ciência política ter sido colonizada pela revolução behaviorista. Nesse sentido, o mainstream da ciência política desconsidera os estudos urbanos, pois desde os anos de 1960 estes se dedicaram mais a salvar as cidades do que a estudá-las, adotando uma retórica excessiva sobre a questão urbana, o que gerou um consenso retórico e um modismo conceitual. ${ }^{4}$ Esse discurso enxerga a cidade com um pessimismo denominado por Judd de "tríptico noir": tragédia, grande drama e futuro desastroso (expresso no título do artigo - "Everything is going to hell"). Para ele, embora dimensôes como pobreza, vigilância, bolhas turísticas e enclaves fortificados estejam presentes em grandes cidades mundo afora, a ênfase quase exclusiva nessas dimensóes confunde a parte com o todo e produz uma distopia nostálgica de algo que não existiu - o bairro operário da solidariedade ou a comunidade de pequeno porte com relaçóes horizontalizadas de poder. Essa postura resulta em um convite para se pregar argumentos retóricos para convertidos.

Em resposta a Judd (2005), Imbroscio (2010) segue a mesma linha de Stone, sustentando que a distância entre os campos é saudável, pois a ciência política em geral partiria de uma visão empobrecida de poder, oriunda no pluralismo, além de sustentar uma separação entre Estado e mercado e se recusar a ser impactada pela literatura crítica. $\mathrm{O}$ autor sustenta que o mainstream da ciência política continua dominado pelo behaviorismo e mais recentemente pela escolha racional, rejeitando o pluralismo metodológico interdisciplinar necessário para se estudar a cidade.

Tenho que dizer que concordo parcialmente com argumentos de ambos os lados desse debate. De um lado, a ciência política tradicional realmente parte de uma visão formalista da produção de políticas e despreza os debates urbanos, inclusive os que poderiam ajudá-la; de outro, os estudos urbanos foram mesmo impactados pelo "tríptico noir" e leem muito pouco a produção sobre política e políticas, desconsiderando contribuiçóes por preconceito ideológico e começando do zero caminhos já trilhados.

A produção brasileira, adicionalmente, tende a abraçar teorias, métodos ou autores de forma única, 
assumindo dimensóes quase identitárias. Isso tem duas consequências negativas para a produção do conhecimento. Primeiro porque leva a um esforço de aplicar o autor, o método ou a teoria de preferência a qualquer objeto, ou então a escolher os objetos de forma a poder aplicar a teoria, e não o inverso. Segundo porque gera uma recusa ao diálogo com outras tradiçóes, mesmo que sejam apropriadas aos temas em questão. Pode parecer óbvio, mas devemos conhecer o máximo possível dos debates (e métodos) existentes e fazer dialogar tradiçóes ou mobilizar métodos e autores sempre que isso for profícuo.

\section{Como entáo estudar a política do urbano, em especial no Brasil?}

A política e as políticas do urbano envolvem basicamente os mesmos elementos da política em geral, mas com importantes especificidades. Estas envolvem principalmente: (i) instituiçóes, agências e processos de produção de políticas; (ii) atores societais, suas relaçóes entre si e com o Estado; e (iii) legados e processos que as produzem. Observemos esses elementos separadamente.

\section{Instituições, agências estatais e processos de produçâo de políticas}

As instituições enquadram a política pelas regras formais, pelas normas sociais e pelos desenhos organizacionais. Isso tem efeitos sobre dinâmicas políticas e sobre o encaixe $(f i t)$ dessas instituiçóes com agentes societais e suas estruturas de ação (Skocpol, 1992). A geografia de tais desenhos institucionais também tem consequências políticas, como mostrou Katznelson (1981) para a formação do sistema partidário nos Estados Unidos.

Curiosamente, apesar da ampla disseminação desses argumentos, a incorporação do neoinstitucionalismo na análise urbana é baixa (Lowndes, 2001). A primeira dimensão institucional central é o federalismo, ao menos no caso brasileiro. A capacidade de influência e de indução federal no Brasil já foi demonstrada, sobretudo nas políticas sociais, por Arretche (2012a), mas isso não é tão claro no caso das políticas do urbano. Entretanto, mesmo que a autoridade decisória formal da maior parte das políticas do urbano seja municipal, as açôes dos vários níveis de governo tornam imprescindível analisá-las simultaneamente em variados desenhos federativos, dependendo do objeto.

A segunda dimensão institucional central diz respeito aos desenhos de agências, organizaçoóes e das próprias políticas. Diferentes formatos criam condiçōes diversas de insulamento, levam à produção de capacidades e influenciam os tipos de conflito político. Esse mecanismo é geral, mas os desenhos das políticas do urbano se espacializam, sobretudo na entrega de serviços e políticas, influenciando a sua efetividade e as relaçóes entre agências e atores dispersos territorialmente. Mais uma vez, o espaço medeia a produção de politics pelas policies.

De forma associada, é preciso destacar as peculiaridades do ciclo de políticas do urbano e, em especial, de sua implementação, já que as cidades são comumente o palco da entrega final de políticas públicas. A cadeia de produção é relativamente curta em uma estrutura de poucas camadas administrativas, e as atividades de decisão e de implementação são ainda mais interpenetradas do que em políticas de produção mais longa, mesmo em metrópoles. No caso das políticas do urbano, embora argumentos do tipo top-down sobre a implementação continuem relevantes, é ainda mais central a consideração do caráter criativo (e não só executivo) das burocracias no âmbito da rua na entrega final das políticas. Essa proximidade dá um caráter interativo às decisóes e à implementação, influenciando-se mutualmente em processos de tentativa e erro e com a recuperação frequente de políticas passadas, de forma similar ao "modelo da lata do lixo" de Cohen, March e Olsen (1972).

Vale dizer que a localização dos equipamentos das políticas e seus traçados espaciais dão à política e às políticas do urbano um caráter ainda mais inercial e dependente da trajetória do que em outras políticas. Como já citei, nesse caso o "onde" define o "quem", beneficiando grupos localizados que se empoderam pela espacialização própria da política, gerando mecanismos de retornos crescentes ainda mais fortes do que em políticas não espacializadas. A mobilização de habitantes de áreas de alta renda protegidas por zoneamento exclusivista constituem um exemplo desse tipo de mecanismo. 
Outro tema de suma importância diz respeito às capacidades estatais. $\mathrm{O}$ conceito aponta elementos centrais para a produção de estratégias bem-sucedidas em termos técnicos e políticos. Entretanto, parece também evidente que carrega certa endogenia, ao designar um resultado (positivo) em vez de especificar os processos e as condições de sua produção. Talvez seja mais apropriado, portanto, analisar os elementos que compóem as capacidades, entendidos de forma relativa e relacional (e não substantivada), pois se trata sempre de recursos em relação aos de outros atores. No caso do urbano, elas envolvem o desenvolvimento de procedimentos e ferramentas espacializados que regulam os conflitos entre atores (em processos participativos, por exemplo), assim como permitam a entrega das políticas.

Uma parte substancial dessas ferramentas envolve microinstituiçóes ou elementos aparentemente técnicos e operacionais, mas que induzem resultados, fazem iniciativas alcançarem seu alvo ou mesmo automatizam açóes do Estado, reduzindo consideravelmente os custos políticos subsequentes. Os chamados instrumentos de política pública (Lascoumes e Le Galés, 2005) estruturam estratégias de produção de políticas, mas não o fazem de forma neutra, e sim informados por visões, teorias e técnicas de intervenção. Ao fazê-lo, definem elegibilidades, beneficiam ou desmobilizam atores e, sobretudo, influenciam resultados. Esses instrumentos são especialmente importantes no urbano pela proximidade com a entrega das políticas, com desenhos ou efeitos espacializados. São muitos os exemplos recentes, mas cito apenas, para concretizar o argumento, o impacto de zoneamentos especiais de interesse social no uso do solo e no planejamento, e da associação entre cartão magnético e controle dos ônibus por GPS nas políticas de transporte público (Campos, 2015).

Todos esses elementos se conectam com os atores estatais - as agências das políticas urbanas e os indivíduos e grupos que as operam. Esses são portadores de interesses próprios irredutíveis a grupos da sociedade, além de disporem de recursos de poder, até mesmo por se posicionarem na cadeia de produção das políticas. Agências e burocracias locais estiveram sempre envolvidas na produção de políticas urbanas no Brasil, mesmo que de forma imbricada com atores privados. Talvez o baixo destaque na- cional a esses atores se origine na baixa capacidade técnica e de gestão de nossos governos locais, partindo da premissa de que não teriam ferramentas para efetivamente influenciar políticas. Mesmo que isso possa ter sido parcialmente verdadeiro em momentos anteriores, os dados existentes sugerem que a capacitação local tem aumentado bastante, ao menos para algumas políticas urbanas (Arretche, 2012b). Um conjunto de pesquisas recentes sobre São Paulo aponta para resultados similares, sugerindo a construção continuada na última década de procedimentos, burocracias e capacidades, ao menos nas políticas de trânsito, transporte público, limpeza urbana, assistência social e controle da atividade imobiliária (Requena, 2014; Campos, 2015; Ralize, 2015; Bichir, Brettas e Canato, 2016; Hoyler, 2014). Fora do Executivo, é evidente a consolidação de atores como o Ministério público, que tem contribuído para abrir os processos decisórios das políticas urbanas e aumentar a sua responsabilização.

Por fim, tem ficado cada vez mais claro que atores buscam seus interesses, mas são também informados por ideais e perseguem preferências substantivas de políticas. Quando atores se conectam no interior de comunidades setoriais, redes de políticas e comunidades epistêmicas (Haas, 1992), ideais e soluçóes também se encontram e se transformam. A frente de pesquisas sobre ideais, agendas e paradigmas chegou ao urbano apenas recentemente com trabalhos sobre difusão ou mobilidade de ideais e soluçóes (Ward, 2006), embora na pesquisa urbana nacional ainda permaneça pouco desenvolvida. ${ }^{5}$

Em suma, destaco a importância de elementos pouco incorporados nas análises de nosso urbano, incluindo o papel do federalismo e dos atores estatais, os desenhos de agências e instituiçóes (muitas vezes espacializados), os ciclos de políticas (mais curtos e mais próximos da entrega final), uma certa dependência da trajetória espacial, as capacidades estatais e os instrumentos de políticas (também espacializados) e a mobilidade de ideais e soluções de políticas públicas.

\section{Atores societais e suas relaçôes}

$\mathrm{Na}$ trajetória da literatura de políticas públicas, o destaque a atores é um elemento central desde as matrizes pluralistas já nos anos de 1940. A política 
do urbano tem seus próprios atores, mas, sobretudo, imprime especificidades ao seu comportamento. Embora cada política conte com atores distintos, sustento a importância de três grupos, além dos atores estatais já mencionados - políticos, capitais do urbano e organizaçóes da sociedade civil.

Em primeiro lugar, devem ser citados atores classicamente destacados desde os debates pluralistas e elitistas - os políticos, especialmente em regimes democráticos. $\mathrm{O}$ acesso a cargos e ao poder via eleiçôes lhes imprime uma lógica que remete à maximização das chances de reeleição. Isso é geral, mas no caso dos políticos de base local os padróes eleitorais de votação têm feições espaciais claras e estáveis, constituindo redutos, mesmo em sistemas eleitorais com distritos plurinominais (Kinzo, Borin e Martins Jr., 2003). A espacialização dos votos e das políticas só aumenta a identificação de beneficiários de cada política, gerando ainda mais incentivos para estratégias espacializadas de credit claiming. Além disso, a imbricação entre Legislativo e Executivo é maior que no âmbito federal, sendo o controle sobre áreas do Executivo ainda mais central para a construção de carreiras políticas baseadas em recursos clientelistas, na mediação política e na construção de acesso entre os eleitores, as instituições políticas e as agências do Estado (Kuschnir, 2000). São pouco frequentes não só os estudos sobre tais processos no Brasil, mas também sobre o Legislativo, o Ministério Público e o Judiciário com atuação local (Couto e Abrúcio, 1995; Andrade, 1998).

Um segundo grupo diz respeito aos capitais do urbano. Refiro-me às empresas privadas cujos ciclos de valorização se ligam à produção da cidade e às políticas do urbano em sociedades capitalistas concessionárias de transportes e limpeza, incorporadoras, construtoras etc. O termo explicita a herança marxista que destaca a economia política para além de suas estratégias empresariais e também os circuitos de valorização que associam dimensões econômicas e políticas. Entretanto, rejeito premissas de captura estrutural do Estado a priori. Momentos de captura da política por grupos econômicos podem acontecer, mas isso é consequência do desenrolar da política e não de alguma estrutura social pré-definida. Para demonstrar sua influência, portanto, é necessário investigar sua ação política (individual ou coletiva) e especificar mecanismos de acesso e influência.

Os capitais do urbano, entretanto, são diferentes considerando suas economias políticas e suas relaçóes com o Estado e com o espaço, como explorado em Marques (2016b). A valorização da terra foi sempre considerada um elemento chave, mas a variedade dos circuitos de valorização sugere maior atençáo para a busca de acesso das empresas ao fundo público. Nesse sentido, novamente os formatos institucionais e os instrumentos de política pública são importantes para analisar, por exemplo, se serviços de transporte ou de coleta de lixo são pagos por passageiro transportado/lixo coletado ou quilômetro rodado (ou por uma combinação entre ambos), trazendo para o centro da análise os detalhes dos instrumentos de pagamento e de regulação dos serviços. As conexôes entre contratos públicos, financiamento eleitoral e produção de políticas são muito conhecidas, mas são pouco mobilizadas como mecanismo de influência sobre políticas públicas. É quase certo que essas conexóes sejam também cruciais nas redes internas dos partidos políticos, veiculando recursos verticalmente e ligando eleiçôes e políticos em várias escalas.

A participação desses capitais nas políticas do urbano tem aumentado e se diversificado, não apenas no Brasil. Para Levi-Faur (2005), isso marca uma nova e sustentada divisão de tarefas entre Estado e setor privado, com a crescente transferência da execução direta de políticas para empresas privadas, mas acompanhada do desenvolvimento de maiores capacidades regulatórias nas mãos do Estado, o que ele denomina "capitalismo regulatório". O resultado náo seria a menor participação do Estado na economia, como defende o neoliberalismo e combatido por seus críticos, mas um Estado diferente, visto que por vezes os aparelhos de regulaçáo teriam porte e gastos até mais significativos.

Trata-se de uma novidade histórica. No capitalismo competitivo do século XIX, o setor privado encarregava-se tanto de produzir políticas - ação capturada pela metáfora de remar (row) -, como de conduzi-las (steer) (Stoker, 1998b). As transformaçóes do fordismo-keynesianismo justamente aparelharam o Estado nesse sentido, ou seja, não só para a produção, mas também para condução das políticas, 
o que ficou conhecido como capitalismo de Welfare. As mudanças ocorridas a partir dos anos de 1970 alteraram novamente a situação o Estado agora concentra-se mais na regulação (steer) que na produçấo efetiva (row), que é cada vez mais realizada pelo setor privado. Os padrōes anteriores não foram substituídos, mas se imbricariam com novos elementos, mudando o funcionamento da economia e do sistema político. Esses deslocamentos demandam análises detalhadas sobre as formas de contrataçăo e provisão de serviços para entendermos a elegibilidade, a responsabilização de decisores e prestadores e o caráter distributivo das políticas.

Uma das formas mais gerais de enquadrar tais transformaçōes é entendê-las como mudanças nos padrôes de governança. Foge aos objetivos deste artigo discutir esse conceito polissêmico detalhadamente. ${ }^{6}$ As definiçóes mais correntes e aceitas, entretanto, utilizam a palavra para designar conjuntos complexos de organizaçóes estatais e não estatais, conectadas por redes (Stoker, 1998a), levando a reorganizaçóes do governo no sentido de tornar permeáveis, interdependentes e, por vezes, dúbias as fronteiras entre os setores público e privado. O conceito é aplicado de forma variada para analisar os formatos heterogêneos de contrataçōes envolvendo parcerias (Davies, 2003), empresas de propósito específico (Judd e Smith, 2007), distritos especiais (Ward, 2006), de forma avulsa ou em grandes projetos urbanos (Raco, 2014).

Para alguns, isso tudo representou uma resposta das organizaçōes estatais à crescente heterogeneidade das sociedades (Pierre, 1998; Peters, 2000; Stoker, 1998a). Assim, o deslocamento analítico para a governança resultou da conclusão de que a produção de políticas em certas condições pode não recorrer à autoridade única do Estado, mas tampouco pode prescindir dele. Resultariam então diversos formatos de governança, segundo condiçôes e decisóes locais (Pierre, 2011). Para críticos como Davies (2003), por outro lado, foi o produto combinado da crise do fordismo, da ascensão da nova direita e do neoliberalismo, partindo da premissa de que a prestação de serviços privados seria sempre superior à pública e negativando a política, supostamente mobilizada apenas por atores públicos.

Parece-me que o mais importante desse debate diz respeito ao deslocamento analítico proposto no estudo de políticas na direçáo dos atores e das arenas relevantes, independentemente de sua localização no Estado ou fora dele (Marques, 2003). O ponto de partida mais apropriado, parece-me, seria concentrar-se em quem governa o quê (e como), quem governa o que o Estado não governa ( $\mathrm{Le} \mathrm{Ga}$ lés, 2011). Os estudos se desdobram, nesse sentido, em análises náo normativas sobre os diferentes conjuntos de atores envolvidos, suas conexóes e as instituiçōes que os cercam (Marques, 2013).

Esses elementos são especialmente importantes para o caso brasileiro, em que diversas formas de relação entre público e privado envolvem arranjos formais e informais na operação das políticas (Marques, 2003). Embora o Estado esteja muito presente nas mais diversas esferas sociais, muitas vezes náo apresenta condiçóes de insulamento $\mathrm{e}$ capacidade para a formulação e a implementação de políticas. Alguns autores mobilizaram a ideia de privatização do Estado para descrever as conexóes entre público e privado, enfatizando a exploraçấo do primeiro pelo segundo no Brasil (Grau e Beluzzo, 1995). Cardoso (1970), por outro lado, desenvolveu a ideia de anéis burocráticos do poder, definidos como círculos de interessados que conectariam setores do Estado com agentes privados nesses setores. $\mathrm{O}$ conceito diferencia a intermediação de interesses presente no país do lobby norte-americano e do corporativismo europeu, mas pouco contribui para especificar os detalhes desses padróes, além de sugerir vínculos intencionais e baixa inércia temporal.

Sugeri, em contrapartida, o conceito de tecido relacional do Estado e de sua permeabilidade, dialogando mais claramente com as teorias do Estado elitista e neoinstitucionalista e mobilizando a análise de redes como método (Marques, 2003). O tecido relacional expressa os padróes de conexão entre atores estatais e não estatais em redes baseadas em relaçôes formais e informais de diversos tipos. Essas redes estruturam o Estado internamente e o conectam com o ambiente político mais amplo que o cerca. A permeabilidade, por sua vez, diz respeito especificamente às conexóes entre o setor privado e o Estado no interior daquele tecido. Esses padróes são mais inerciais e menos intencionais que os descritos pelos anéis burocráticos, visto que o tecido 
relacional do Estado é historicamente construído ao longo dos processos de produção dos setores de políticas. A partir dessa dimensão é possível compreender como o Estado pode ser ao mesmo tempo mais central na produçáo de políticas, menos insulado e mais interpenetrado por agentes privados, do que considerado pela literatura internacional.

Por fim, é preciso destacar vários tipos de atores coletivos da sociedade civil. No caso brasileiro, esses atores tiveram um papel direto na redemocratização, na formulação da Constituiçáo de 1988 e nas reformas setoriais das políticas do período militar. A partir dos anos de 1990, os movimentos de corte mais tradicional - sindicatos e associaçōes de bairro reduziram sua visibilidade na cena pública, mas passaram a participar de forma intensa das novas institucionalidades participativas entáo criadas conselhos, conferências, entre outros (Gurza Lavalle e Barone, 2015). Por outro lado, movimentos de corte diverso estáo presentes na cena política, com demandas identitárias, de condiçōes minoritárias e pautas urbanas (Alonso e Mische, 2016).

Esses deslocamentos no ativismo societal foram acompanhados por fortes transformaçōes na literatura. Na verdade, dentre todos os atores destacados, esses são aqueles sobre os quais acumulamos conhecimento mais sistemático no Brasil. Se até os anos de 1990 a questáo central envolvia os graus de autonomia dos movimentos, desde entáo a agenda de pesquisa incorporou as múltiplas formas de relação que esses movimentos têm entre si e com as instituiçôes políticas, tecendo comunidades de políticas e seus entornos e cruzando as fronteiras entre Estado e sociedade civil por diversas formas de encaixe (Gurza Lavalle, Castello e Bichir, 2008). Isso tem aproximado positivamente os estudos de associativismo, movimentos sociais e políticas públicas. Nesse sentido, a ideia já mobilizada de governança pode deixar de designar os novos arranjos de participação privada (pró-lucro) em políticas em contraposiçāo a instâncias participativas e integrar as diversas formas de inserção de agentes não estatais em políticas públicas, conectados entre si e com agentes do Estado no interior do seu tecido relacional.

Resumindo, portanto, destaco três conjuntos de atores com especificidades no urbano, consi- derando suas relaçóes com o Estado e o espaço políticos, capitais do urbano e organizaçóes e movimentos da sociedade civil, sempre pensados de forma conectada no interior das redes dos setores de políticas em constante transformação.

\section{Legados históricos e o desenrolar da politica e das politicas}

O terceiro e último elemento a considerar diz respeito aos legados históricos. Em sentido geral, políticas acontecem nos ambientes formados (i) pela construção histórica conjunta dos Estados e das sociedades; (ii) pelas relaçôes que os conectam entre si (incluindo suas gramáticas políticas); e (iii) pela conformação dos objetos de intervenção das políticas. As políticas do urbano, especificamente, são emolduradas por legados relativos às estruturas institucionais das políticas, aos seus atores e às próprias cidades, suas estruturas e características. Por isso, processos históricos diversos geram grandes diferenças entre países e cidades com relação, por exemplo, à centralização política dos governos nacionais, à presença e às capacidades das burocracias e dos empresários e às suas formas de representação de interesse, aos instrumentos de intervenção ou de regulação estatal e às estruturas fundiárias das cidades.

No caso brasileiro, alguns elementos devem ser considerados. Entre nós, a ação do Estado sobre o urbano iniciou-se de modo significativo apenas no final do século XIX com os serviços concedidos a empresas privadas nacionais, que após alguns anos os repassaram a empresas estrangeiras, como nos casos de bondes de tração animal, iluminação pública, água e esgotos e, posteriormente, bondes a tração elétrica. Nos anos de 1910 e 1920, instituiçóes estatais da administração direta encamparam os serviços privados dos mesmos setores pelas dificuldades de importação com a Primeira Guerra Mundial e a Grande Depressão. Esse deslocamento foi também impulsionado (e impulsionou) os cada vez mais presentes produtores nacionais de materiais e obras, assim como as nascentes comunidades de políticas locais.

No início da década de 1960 e, em especial, depois do golpe militar de 1964, constituíram-se empresas públicas integradas em sistemas federais 
em políticas como saneamento, eletricidade, trens metropolitanos e habitação, embora outras, como limpeza urbana, uso do solo e transportes sobre pneus, tenham permanecido locais e sem regulação federal. Em várias áreas de política pública a produção foi massificada, mas com graves problemas de qualidade, targeting, gigantismo e corrupção, como já amplamente discutido (Draibe, 1989). Nesse terceiro período, o setor privado esteve afastado da prestação direta das políticas, mas operou fortemente como contratado para a realização de projetos, obras e serviços (Camargos, 1993).

Os anos de 1980 assistiram à desagregação das agências nacionais responsáveis pelas políticas do regime militar para as cidades. Já havia nesse momento uma complexa rede urbana com grandes metrópoles marcadas por intensa pobreza e forte segregaçáo residencial, periferias sem infraestrutura e grandes desigualdades de acesso a políticas, como mostra clássicos de nosso urbano (Maricato, 1982; Kowarick, 1979).

A peculiar importância econômica e política dos capitais do urbano e, em especial, da construção civil, no país impactou essa trajetória histórica. Em contribuição já clássica, Lessa e Dain (1982) sugeriram a existência de uma tríplice aliança no capitalismo nacional, com o Estado produzindo infraestrutura e bens intermediários, o setor privado estrangeiro concentrando-se na indústria de transformação moderna e o setor privado nacional especializando-se no capital bancário, comercial e em indústrias de baixa composição orgânica, como a construção civil. Na verdade, o setor de construção foi em parte fomentado pelo próprio Estado brasileiro, pois suas contrataçóes o capitalizaram e o especializaram desde os anos de 1950. O regime militar e depois as transformaçóes da economia brasileira nos anos de 1990 só fortaleceram essa especialização, diversificando os portfolios dessas empresas e mesmo internacionalizando-as. Como resultado, as construtoras estão hoje entre os principais capitais nacionais, vivem de contratos com o Estado, constroem e mantêm vínculos com governos e agências estatais, sempre financiam campanhas eleitorais e com frequência estão envolvidas em escândalos de corrupção, como se tornou corrente no noticiário recente.

No caso das cidades, a importância desses atores é ainda maior e diversificada, pois envolve tam- bém outros tipos de capitais do urbano, como os prestadores de serviços urbanos (empresas de ônibus e limpeza urbana), as construtoras de obras públicas e os incorporadores (Marques, 2016b). Embora inexistam estudos sistemáticos, informaçóes esparsas sugerem uma grande interpenetração das elites políticas e econômicas locais com esses capitais, gerando múltiplos canais para a influência do setor privado sobre as políticas do urbano. O tema também envolve a centralidade da terra nos processos de valorizaçáo de capitais do urbano e das elites locais, dificultando muito a produção de políticas de regulação da terra.

O declínio das políticas do regime militar permitiu um importante ciclo de inovação de políticas do urbano nos anos de 1990, trazendo novas ações, como urbanização de favelas, regularização de loteamentos, zoneamentos especiais, locação social, mutirão cogerido, entre outras. Esse processo de inovação ganhou escala nacional nos anos 2000 com a criação do Ministério das Cidades, novas instituiçóes, fundos, conselhos e planos nacionais, embora com baixo grau de insulamento e de capacidades. O investimento federal também voltou com o programa Minha Casa Minha Vida e o PAC, mas desarticulado e em contradição parcial com os sistemas nacionais de políticas então em construção, em especial o Sistema Nacional de Habitação de Interesse Social. Embora tenham ocorrido privatizaçóes e concessóes, estas pouco impactaram as políticas urbanas. Simultaneamente, os governos locais aumentaram suas capacidades, desenvolvendo burocracias, agências, conselhos e fundos, o que complexificou ainda mais a questão federativa.

A maior parte dos serviços continuou sendo prestada por entidades públicas, embora com a participação diversa de empresas privadas, para além das clássicas contrataçooes de projetos de engenharia e construção. Foram também constituídas entidades regulatórias, mas sua atuação ainda não logrou desfazer a simbiose e a superposição entre Estado e atores privados nas políticas do urbano. Esse arranjo ganhou escala inédita com o projeto Porto Maravilha no Rio de Janeiro, concedendo todos os serviços e políticas de uma região da cidade a um agente privado por um longo período, em diálo- 
go com grandes projetos internacionais, como o da Olimpíada de Londres (Saruê, 2015).

Também a política do urbano foi renovada desde a redemocratização, pelo menos em duas dimensões. Em primeiro lugar, intensificou-se a competição eleitoral e partidária local, tornando urgente a compreensão das estratégias e das carreiras dos políticos locais, aspectos ainda pouco explorados no geral (Limongi e Mesquita, 2011) e nos detalhes (Kuschnir, 2000). A atual dinâmica também trouxe transformaçóes para o ativismo social de um cada vez mais heterogêneo campo de organizaçóes da sociedade civil, muitas vezes imbricado complexamente no sistema político e com as agências governamentais e suas ações (Gurza Lavalle, Castello e Bichir, 2008). A produção de políticas, por seu turno, tem sido intensamente influenciada por políticos, organizaçóes estatais, burocracias e mecanismos de participação social, em processos sempre marcados pelas localizaçóes e fluxos que os definem e constituem.

O Estado brasileiro, portanto, esteve presente desde o final do século XIX na produção e na regulação de políticas, mas se apoiando sempre no setor privado para diversas tarefas. Esses padróes foram renovados recentemente com a relevância redobrada do federalismo, o aumento das capacidades estatais em vários níveis, inclusive regulatórias, e com políticas mais diversificadas, em parte pela crescente importância da política local e do cada vez mais dinâmico ativismo societal.

\section{Ao invés de concluir}

Como vimos, os debates internacionais se iniciaram no chamado community power debate, passaram pela sociologia marxista, pela teoria dos regimes e das máquinas de crescimento e, mais recentemente, concentraram-se nos novos arranjos e governança. Infelizmente, consolidou-se uma divisão de campos distintos para compreender as cidades e a política. A superação desse problema pressupóe entender o espaço como dimensão constitutiva da política e das políticas e, simultaneamente, como pressuposto e resultado das práticas políticas e das açóes do Estado. Por outro lado, é imprescindível considerar o Estado e as insti- tuiçóes políticas um lócus de dinâmicas e processos em si, e não apenas um mero rebatimento de processos produzidos fora deles. Isso não significa a adoção de análises estatistas, mas, ao contrário, indica a inserção de diversos atores - estatais e não estatais - nos contextos institucionais e relacionais e na produção de políticas com dimensóes espaciais profundas.

Creio ser urgente análises sobre a política e as políticas do urbano que adotam tais premissas. Esse exercício depende da incorporação concomitante de três conjuntos de elementos. Em primeiro lugar, instituições, agências e processos de produção de políticas com destaque para o federalismo, os atores estatais, as agências, os processos de produção de políticas com ciclos mais curtos e mais próximos do nível da rua e com dependência espacial, os instrumentos e as ideias de políticas. Em segundo lugar, atores societais incluindo políticos, capitais e atores associativos - pressupondo suas relaçóes entre si e com o Estado em constante transformação. Por fim, os legados que produziram esses elementos; no caso das políticas do urbano, foram marcados por um arranjo peculiar em que o Estado sempre esteve presente, mas com formas variadas de participação privada, mediadas por instituições formais e também por padróes de relação e permeabilidade. Recentemente, esses padrôes vêm sendo reconstituídos pelo federalismo, por um aumento das capacidades estatais e por um leque mais amplo de políticas impulsionadas pelo crescente dinamismo político local.

\section{Notas}

1 É interessante notar como usamos a palavra "dinâmica” no sentido metafórico de transformação ou mudança, em vez de "movimento" ou "deslocamento", quando se trata de transformações que também acontecem no espaço e não só no tempo.

2 Para uma discussão detalhada desses argumentos, ver Marques (2016a).

3 Stone (2010) afirma que para o mainstream da ciência política, a política do urbano é sobre "educação e coleta de lixo".

4 É impressionante como os estudos urbanos geram novos conceitos e totalizaçóes de vida efêmera. Alguns 
dizem respeito a fenômenos novos e resistem melhor ao tempo, como gentrificação e cidades globais, mas outros desaparecem, como megacidades. Um exemplo recente é a mobilidade de políticas (Peck e Theodore, 2010), que enfocam processos já discutidos e partem de uma crítica muito limitada da literatura que ignora a produção sobre ideias e agenda em políticas públicas.

5 Vale assinalar que a única subárea de nossos estudos urbanos a explorar a circulação de ideias analisa grandes projetos, em que essa circulaçáo se aproxima da venda e/ou imposição de modelos, sendo criticada com base na literatura pós-colonial (Vainer, 2014). Dadas essas ênfases, as diversas outras formas de circulação permanecem entre nós muito pouco exploradas e teoricamente desinformadas dos debates sobre políticas.

6 Em Marques (2013) resenho criticamente os usos do conceito no Brasil e proponho um conceito alternativo, mapeando os padróes de governança presentes na metrópole paulistana. Internacionalmente, ver Rhodes (2007) e Stoker (1998b).

\section{BIBLIOGRAFIA}

ALONSO, Angela \& MISCHE, Ann. (2016), "Changing repertoires and partisan ambivalence in the new Brazilian protests. Bulletin of Latin American Research, 36 (1), pp. pp. 144-159.

ANDRADE, Regis. (1998), Processo de governo no município e no estado: uma análise a partir de São Paulo. São Paulo, Edusp.

ARRETCHE, Marta. (2012a), Democracia, federalismo e centralização no Brasil. Rio de Janeiro, Fiocruz/FGV.

(org.). (2012b), Capacidades administrativas dos municipios brasileiros para a politica habitacional. Brasília, Ministério das Cidades/CEM.

BICHIR, Renata; BRETTAS, Gabriela \& CANATO, Pamella. (2016), The politics of the social assistance policy in São Paulo. São Paulo, CEM (mimeo.).

CAMARGOS, Regina. (1993), Estado e empreiteiros no Brasil: uma análise setorial. Campinas, dissertação de mestrado, IFCH - Unicamp.

CAMPOS, Marcos. (2015), Permeabilidade do Estado e redes sociais no transporte público urbano nos anos 2000. São Paulo, dissertação de mestrado, Departamento de Ciência Política - USP.
CARDOSO, Fernando H. (1970), "Planejamento e política: os anéis burocráticos”, in Bety Lafer, Planejamento no Brasil, São Paulo, Perspectiva.

CASTELLS, Manuel. (1983), A questão urbana. Rio de Janeiro, Paz e Terra.

COHEN, Michael; MARCH, James \& OLSEN, Johan. (1972), "A garbage can model of organizational choice". Administrative Science Quarterly, 17 (1): 1-25.

COUTO, Cláudio \& ABRUCIO, Fernando. (1995), "Governando a cidade: a força e a fraqueza da Câmara Municipal”. São Paulo em Perspectiva, 9 (2): 57-65.

DAHL, Robert. (1961), Who governs? Democracy and power in an American city. New Haven, Yale University Press.

DAVIES, Jonathan. (2003), "Partnerships versus regimes: Why regime theory cannot explain urban coalitions in the UK". Journal of Urban Affairs, 25 (3): 253-269.

DAVIES, Jonathan. \& Imbroscio, David (orgs.). (2005), Theories of urban politics. Nova York, Sage.

DRAIBE, Sônia. (1989), "O Welfare State no Brasil: características e perspectivas”, in Anpocs, Ciências Sociais Hoje, São Paulo, Anpocs/Vértice.

ELKIN, Stephen. (1985), "Twentieth century urban regimes". Journal of Urban Affairs, 7 (2): 11-28.

GURZA LAVALLE, Adrián \& BARONE, Leonardo. (2015), "Conselhos, associações e desigualdades”, in M. Arretche (org.), Trajetórias das desigualdades, São Paulo, Editora da Unesp/CEM.

GURZA LAVALLE, Adrián; Castello, Graziela \& BICHIR, Renata. (2008), "The backstage of civil society in São Paulo". IDS Working Paper Series, 299.

GRAU, Eros \& BELLUZZO, Luis. (1995). "A corrupção no Brasil”. Revista Brasileira de Estudos Políticos, 8: 7-20.

HAAS, Peter. (1992), "Epistemic communities and international policy coordination”. International Organization, 46 (1): 1-35.

HARDING, Alan. (1997), "Urban regimes in a Europe of the cities?”. European Urban and Regional Studies, 4 (4): 291-314.

HARVEY, David. (1980), Justiça social e a cidade. 
São Paulo, Hucitec.

HOYLER, Telma. (2014), Incorporação imobiliária e intermediação de interesses em São Paulo, dissertação de mestrado, Departamento de Ciência Política - USP.

HUNTER, Floyd. (1953), Community power structure: A study of decision makers. Chapel Hill, University of North Carolina Press.

IMBROSCIO, David. (2000), "Keeping it critical: resisting the allure of the mainstream", in J. Davies e D. Imbrosco (orgs.), Critical urban studies, Albany, Sunny Press.

JOBERT, Bruno \& MULLER, Pierre. (1987), L'État en action. Paris, PUF.

JOHN, Peter. (2005), "Why study urban politics?", in Jonhatan Davies e David Imbroscio (orgs.), Theories of urban politics, Nova York, Sage.

JUDD, Dennis. (2005), "Everything is going to hell: urban scholars as end-times prophets". Urban Affairs Review, 41: 119-131.

JUDD, Dennis \& Smith, John. (2007), “The new ecology of urban governance: special-purpose authorities and urban development", in R. Hambleton e J. Gross (orgs.), Governing cities in a global era. Nova York, Palgrave.

KATZNELSON, Ira. (1981), City trenches: urban politics and the patterning of class in the United States. Chicago, University of Chicago Press.

KINZO, Maria; BORIN, Ivan \& MARTINS Jr., José. (2003), "Padróes de competição eleitoral na disputa para a câmara paulistana (19922000). Novos Estudos Cebrap, 65: 45-56.

KOWARICK, Lúcio. (1979), A espoliação urbana. São Paulo, Paz e Terra.

KUSCHNIR, Karina. (2000), O cotidiano da politica. Rio de Janeiro, Zahar.

LASCOUMES, Pierre \& LE GALÉS, Patrick. (2005), Gouverner par les instruments. Paris, Press de Sciences Po.

LE GALÉS, Patrick. (1995), "Du gouvernement dês villes à la gouvernance urbaine". Revue Française de Science Politique, 1: 57-95.

. (2011), "Urban policies in Europe: what is governed?", in G. Bridge e $\mathrm{S}$. Watson (orgs.), The New Blackwell Companion to the City. Oxford, Blackwell.

LEFÉBVRE, Henri. (1976), Espacio y politica. Bar- celona, Península.

LESSA, C. \& DAIN, S. (1982), "Capitalismo associado: algumas referências para o tema Estado e desenvolvimento", in L. G. Belluzo e L. Coutinho (orgs.), Desenvolvimento capitalista no Brasil: ensaios sobre a crise, São Paulo, Brasiliense.

LEVI-FAUR, D. (2005), "The global diffusion of regulatory capitalism". The Annals of the American Academy of Political and Social Science, 598: 12-25.

LIMONGI, Fernando \& MESQUITA, Lara. (2011), "Estratégia partidária e clivagens eleitorais", in L. Kowarick e E. Marques (orgs.), São Paulo: novos percursos e atores. São Paulo, Editora 34/CEM.

LOJKINE, Jean. (1981), O Estado capitalista e a questão urbana. São Paulo, Martins Fontes.

LOWNDES, Vivianne. (2001), "Rescuing aunt sally: taking institutional theory seriously in urban politics". Urban Studies, 38 (11): 1593-1971.

MARICATO, Ermínia (org.). (1982), A produção da casa (e da cidade) no Brasil industrial. São Paulo, Alfa-Ômega.

MARQUES, Eduardo. (2003), Redes sociais, instituiçóes e atores políticos no governo da cidade de São Paulo. São Paulo, Annablume/Fapesp.

. (2013), "Government, political actors and governance in urban policies in Brazil and São Paulo". Brazilian Political Science Review, 7 (3): 8-35.

(2016a), "Notas sobre políticas e política urbanas". CEM: Working Paper Series, 18. (2016b), "Capitais do urbano". Novos Estudos Cebrap, 105: 15-33.

MASSEY, Doreen. (2005), For space. Nova York, Sage.

MÉO, Guy di. (1991), L’homme, la societé, l'espace. Paris, Anthropos.

MILLS, Charles. (1956), A elite do poder. Rio e Janeiro, Zahar.

MOLOCH, Harvey. (1976), "The city as a growth machine". The American Journal of Sociology, 82 (2): 309-332.

PAULA, Pedro de. (2014), As parcerias público-privadas de metrô de São Paulo. Dissertação de mestrado, São Paulo, Faculdade de Direito - USP. 
PECK, Jamie \& THEODORE, Neil. (2010), "Mobilizing policy: models, methods, and mutations". Geo Forum, 41: 169-174.

PETERS, Guy. (2000), "Governance and comparative politics", in J. Pierre (org.), Debating governance: authority, steering and democracy. Oxford, Oxford University Press.

PIERRE, Jon (org.). (1998), Partnerships in urban governance: European and American perspectives. Nova York, Palgrave.

PIERRE, Jon. (2011), The politics of urban governance. Londres, Palgrave/McMillan.

PINÇON-CHARLOT, Monique; PRETECEILLE, Edmond \& RENDU, Paul (1986), Ségrégation urbaine: classes sociales et équipament colletifs région parisienne. Paris, Anthropos.

RACO, Mike. (2014), "Delivering flagship projects in an era of regulatory capitalism: State-led privatization and the London Olympics 2012. International Journal of Urban and Regional Research, 38 (1): 176-197.

RALIZE, Samuel. (2015), Coleta de lixo em São Paulo: atores, estratégias e histórico de formação do setor. Dissertação de mestrado, São Paulo, Departamento de Ciência Política - USP.

REQUENA, Carolina. (2014), Politicas públicas de mobilidade em São Paulo: instituiçôes e atores. Dissertação de mestrado, São Paulo, Departamento de Ciência Política - USP.

RHODES, Ron. (2007), "Understanding governance: ten years on”. Organization Studies, 28 (8): 1243-1264.

SARUÊ, Betina. (2015), Grandes projetos urbanos e a governança das cidades: o caso do Porto Maravilha. Dissertação de mestrado, São Paulo, Departamento de Ciência Política - USP.

SCOTT, James. (1998), Seeing like a State: how certain schemes to improve the human condition have failed. New Haven, Yale University Press.

SKOCPOL, Theda. (1992), Protecting soldiers and mothers. Cambridge, Belknap Press.

STOKER, Gerry. (1998a), "Public-private partnerships and urban governance", in J. Pierre (org.), Partnerships in urban governance, Nova York, Palgrave.

. (1998B), "Governance as theory: five propositions". International Social Science Journal, 50 (155): 17-28.
STONE, Clarence. (1993), "Urban regimes and the capacity to govern: a political economy approach". Journal of Urban Affairs, 15 (1): 1-28. (2010), "Foreword", in J. Davies e D. Imbroscio (orgs.), Critical urban studies. Albany, Sunny Press.

TOPALOV, Christian. (1973), Les promoteurs immobiliers: contribution à l'analyse de la production capitaliste du logement en France. Paris, Université René Descartes.

TORRES, Haroldo. (2005), "Políticas sociais e território: uma abordagem metropolitana”, in $\mathrm{E}$. Marques e H. Torres (orgs.), São Paulo: segregação, pobreza urbana e desigualdade social, São Paulo, Senac.

VAINER, Carlos. (2014), "Disseminating 'best practice'? The coloniality of urban knowledge and city models", in S. Parnell e S. Oldfield (orgs.), The Routledge handbook of cities of the global South. Nova York, Routledge.

WARD, Kevin. (2006), “'Policies in motion', urban management and State restructuring the trans-local expansion of business improvement districts". Internacional Journal of Urban and Regional Research, 30 (1): 54-75. 


\section{EM BUSCA DE UM OBJETO ESQUECIDO: A POLÍTICA E AS POLÍTICAS DO URBANO NO BRASIL}

\section{Eduardo Cesar Leão Marques}

Palavras-chave: Política urbana; Políticas públicas urbanas; Cidades; Estudos urbanos; Ciência política

Este artigo discute um tema de grande importância, mas que curiosamente foi muito pouco estudado no Brasil - a política (politics) das cidades, em especial das grandes cidades. É surpreendente que o Brasil tivesse $84 \%$ de sua população vivendo oficialmente em áreas urbanas em 2010, mas não tenha desenvolvido um debate denso dedicado à política de suas cidades. O tema foi analisado apenas indiretamente pelos estudos urbanos, como uma dimensão derivada de processos societais, e pela ciência política, como um assunto menor, derivado de dinâmicas políticas situadas em outras escalas. Esse artigo pretende trazer o tema para o centro da análise, refletindo sobre as especificidades da política do urbano, discutindo criticamente as várias tradiçôes presentes nos debates nacionais e internacionais e sugerindo caminhos para a construção de tal enfoque para as cidades brasileiras.

\section{IN SEARCH OF A FORGOTTEN SUBJECT: THE POLITICS AND THE POLICIES OF THE URBAN IN BRAZIL}

\section{Eduardo Cesar Leão Marques}

Keywords: Urban politics; Urban public policies; Cities; Urban studies; Political science

This article discusses a theme of great importance, but that is curiously little studied in Brazil: the city politics, and especially its metropolises. It is unusual that Brazil had $84 \%$ of its population living officially in cities, but had never developed a dense debate dedicated to the politics of its cities. The theme was analyzed only indirectly by the field of urban studies as a secondary dimension derived of social processes, as well as by political science as a minor subject, derived by political dynamics operating at other scales. This article intends to bring the subject to the center of the analysis, taking into account the specificities of urban politics, discussing critically the various traditions present in the national and international debates and suggesting a path for the construction of the line of analysis of the subject for Brazilian cities.

\section{A LA RECHERCHE D'UN OBJET OUBLIE : LA POLITIQUE ET LES POLITIQUES URBAINES AU BRESIL}

\section{Eduardo Cesar Leão Marques}

Mots-clés: Politique urbaine; Politiques publiques urbaines; Villes; Études urbaines; Science politique

Cet article aborde un sujet très important mais qui, curieusement, a été très peu étudiée au Brésil. Il s'agit de la politique (politics) des villes, en particulier des grandes villes. Il est surprenant de savoir qu'en 2010 le Brésil comptait $84 \%$ de sa population vivant officiellement dans les zones urbaines et qu'il n'ait jamais développé un débat dense consacré à la politique de ses villes. Le thème n'a été abordé qu'indirectement par des études urbaines, comme une dimension dérivée des processus sociaux, ainsi que par les sciences politiques, comme un sujet mineur, dérivé de dynamiques politiques situées sur d'autres échelles. Cet article a pour but de porter ce sujet au centre de l'analyse, en une réflexion à propos des spécificités de la politique de l'urbain, tout en discutant de façon critique les différentes traditions présentes dans les débats nationaux et internationaux et en suggérant des voies pour la construction d'une telle approche pour les villes brésiliennes. 